\title{
Inclusion and online learning opportunities: designing for accessibility
}

Elaine J. Pearson* and Tony Koppi**

*Special Needs Computing Research Unit, University of Teesside

**Director, Educational Development and Technology Centre (EDTeC), University of

New South Wales

email:e.pearson@tees.ac.uk,tkoppi@unsw.edu.au

Higher education institutions worldwide are adopting flexible learning methods and online technologies which increase the potential for widening the learning community to include people for whom participation may previously have been difficult or impossible. The development of courseware that is accessible, flexible and informative can benefit not only people with special needs, but such courseware provides a better educational experience for all students.

This paper discusses an evaluation of WebCT in practice at University of New South Wales (UNSW). The objective was to assess the accessibility of WebCT for people with disabilities - sensory, cognitive and physical. The guidelines provided by the World Wide Web Consortium (W3C) (Web Content Accessibility Guidelines 1.0, http:/lwww. w3.org/Tr/WAI-WEBCONTENT), checking mechanisms including the Bobby Web page analysis tool, developed by CAST (http://cast.org/bobby/), and learner centred design methods provided the basis for the evaluation. The approach involved extensive evaluation of existing courses by the researcher, discussion with and survey of WebCT designers, and the involvement of students with disabilities through interview and focus groups. Issues considered include: the provision of alternative information; structure, presentation and organization of content and navigational elements; and accessibility with assistive technologies.

The results reveal that many barriers to accessibility can be overcome through awareness of design issues, and that there is a need for practical advice for academics. The aim is to present a case study of best practice in the design of accessible courseware incorporating design strategies that will enable students with various disabilities to take advantage of the 'just in time, just for me' approach. 


\section{Introduction}

Developments in online learning can present opportunities for a more inclusive education for students with disabilities. Online learning facilitates real flexibility in the time and place for learning; independence is increased through the availability of online learning resources, and there is less reliance on the assistance of helpers such as library staff or note-takers. The ability to submit work electronically can release the students from the costs in time and resources in obtaining physical access. Communication can be improved - computer technology can give voice to those without, both literally and figuratively. Communication devices such as chat rooms, discussion groups and email can enable students to participate without prejudice or embarrassment.

The same developments, however, can also pose further barriers to those with disabilities. Web-based learning materials tend to be heavily text-based, and students may have difficulty in reading or comprehending text or distinguishing colours. Many have difficulty with organization, structure or memory, they may find material difficult to navigate, poorly structured or complex, or the interface may be inconsistent. Students with mobility problems, limited motor control or vision impairment may not be able to use a keyboard or mouse. The increasing use of multimedia can be beneficial in providing an enriched environment, but it can also be a barrier to those who cannot see or hear audio, video and animations. Furthermore, the growth in overseas students and distance learning means that there are increasing numbers who may not be fluent in the language of instruction.

The trend towards development of courses and resources online with the support of a virtual learning environment (VLE) such as WebCT and Blackboard presents both opportunities and challenges in the creation of flexible, informative and accessible educational materials. Part of the challenge is to provide opportunities to the individuals of a wide and varied community, some of whom might not otherwise be able to participate in higher education. People with disabilities face particular barriers to inclusion and the move to online learning may facilitate the lifting of some of these barriers.

There is an increasing awareness of the need to make Web sites accessible to everyone regardless of ability/disability, with a legal imperative coming from the Disability Discrimination Acts in the United Kingdom (http://www.disability.gov.uk/index.html) and Australia (http://www.deet.gov.aularchiveliaelanalysis/ddaedcon.htm), and the Disabilities Act (http://www.wrightslaw.com/info/section504.ada.peer.htm) in the United States. Guidelines, including Web Content Accessibility Guidelines 1.0 (W3C), and 'Web accessibility resources: quick tips to make Web sites accessible' (http:/lgenasys. usm.maine. edulaccess.htm) exist to aid developers of Web sites, and an increasing number of sites display the 'Bobby Approved' logo.

However, learning environments and resources for online teaching have other requirements for accessibility beyond functional considerations and the use of 'ALT' (alternative text) tags. Care needs to be taken with the navigation, structure, content design and communication aspects, and learner-centred design is crucial to ensure that online learning is accessible to students with disabilities.

Most discipline-based academic course developers are stretched to keep abreast of technical developments. Often online courseware development is carried out in addition to their normal workload and they have little time to learn programming skills or understand the technical terminology used in many of the guidelines, such as those provided by W3C. 
Teaching with technology is not something that can easily be picked up along the way as something to be done off the side of the desk while engaged in more important or timeconsuming activities such as research. (Bates, 2000)

Additionally, many of the existing guidelines (Leung, Owens, Lamb, Smith, Shaw and Hauff, 1999) lack practical examples for implementation and are themselves too technical to be easily followed and understood by academic courseware developers. Furthermore, the guidelines tend to concentrate on the functional aspects of Web design and the needs of users with sight or physical impairments, while there is a lack of attention to the needs of people with cognitive or learning disabilities. The guidelines also fail to address learnercentred design of online courseware. There is also a paucity of advice available specifically aimed at the design and development of accessible educational courseware for academic developers.

A set of guidelines was required which are specifically tailored to learning and teaching in higher education and to Web-based learning resources in particular. These guidelines needed to incorporate details of potential barriers to access, practical examples for implementation of accessible solutions and reference to the related W3C guidelines.

This paper presents a case study of best practice in the development of courses in $W e b C T$ (and also has generic application), taking account of the needs of people with a wide range of special needs. Rather then focus on particular categories of disability, the approach is to consider the components and design issues concerned with the development of courseware in terms of the difficulties that students with disabilities might face in accessing them. Addressing those issues has provided a blueprint for online courseware development that represents not only a design strategy for people with special needs but is equally applicable to learner-centred courseware design in general.

\section{The partners}

This project is a collaboration between the Special Needs Computing Research Unit (SNCRU) of the University of Teesside and the Educational Development and Technology Centre (EDTeC) of the University of New South Wales. It has been supported by a Study Abroad Fellowship from The Leverhulme Trust, UK. Members of the SNCRU have carried out extensive research and development in the application of computer technology for people with physical and learning disabilities and the senior author of this paper provided the research expertise in this area. Current research interests within SNCRU include development of a symbols-based managed learning environment for students with severe disabilities; assessment, remediation and development of language in children with special educational needs; and investigation of Autistic Spectrum disorders.

The Educational Development and Technology Centre (http://www.edtecunsw.edu.au) provides services in the promotion and development of institution-wide support for online learning using WebCT. Part of EDTeC's remit is to investigate means of making education more accessible, through technology, to people with disabilities. The centre's support enables teaching staff to develop online learning environments for themselves. As of March 2002 there were more than 600 courses online with more than 21,000 students enrolled on those courses. 


\section{Some definitions}

Accessible design in this context refers to the means by which the content and presentation of an online educational experience enables participation by every student regardless of the browser, browser settings or assistive technology they may be using. The goal should be to enable, as far as possible, the same educational experience for everyone. One should recognize, however, that it may be impossible to cater for all needs, all of the time, but care needs to be taken to provide alternatives when particular needs cannot be met.

Assistive technology can be defined as devices, tools, hardware or software that enable people with disabilities to use the computer. Screen readers, screen magnifiers, alternative keyboards or input devices, voice recognition software and text-only browsers are some of the main examples of assistive technology.

Inclusion refers to the design of educational environments to take account of the needs of all learners, providing access to a learning experience at a pace and level to suit the learner. Online learning presents opportunities for more inclusive education through the just in time, just for me' approach - offering flexibility in the time, place, mode and pace of learning (Collis and Moonan, 2001).

\section{Evaluation methodology}

As part of its mission to encourage inclusive practices in educational development, EDTeC aims to encourage staff developing courses in WebCT (designers) to attain, in the first instance, compliance with Priority Level One of the W3C Web accessibility guidelines. Priority One means that the designer is satisfying the basic requirements for access to Web documents (W3C). This is in line with WebCT s own stated aim (WebCT and Accessibility, http://www.webct.com/service/).

In order to identify the accessibility problems related to the design of courses delivered through an online learning environment, and to propose solutions, an evaluation was carried out of existing courses at UNSW, with the consent of the designers concerned. The process involved a combined qualitative and quantitative approach including:

- extensive evaluation of WebCT courses developed at UNSW;

- discussion with and survey of designers;

- interviews with students with disabilities; and

- practical evaluation by students of the accessibility of courses using assistive technologies.

The evaluation was based on the guidelines provided by W3C 'Web Content Accessibility Guidelines 1.0'; analysis of the courses using the Bobby Web site validation tool; testing with other available checking mechanisms (for example, graphics turned off and monitor set to high contrast); and also with regard to courseware design methods.

The W3C guidelines are produced as part of the W3C Web Accessibility Initiative and provide a guide to ensuring the accessibility of functional aspects of a Web site. There are fourteen guidelines or general principles, each with a set of checkpoints, and the rationale 
behind each guideline. Web Bobby is a tool which provides a crude but indicative analysis, allowing the designer to check the extent to which their courseware has met the criteria of the $\mathrm{W} 3 \mathrm{C}$ guidelines.

However, evaluation of a learning environment which takes account of the requirements of those with sensory and learning disabilities also requires analysis of the structure, presentation, content and navigational aspects. For this the principles of learner-centred courseware design (Figure 1) were employed. A model of courseware design that combines content design, navigational design and visual design but is informed at all stages by the learner model (Pearson and Green, 1999) is the one on which this evaluation is based.

Briefly, the model incorporates content (design of learning materials and activities), navigational design (flow of control and structure), visual modelling (user interface, icons, graphics) and, crucially, learner modelling (who the learner is, what the learning needs are, how the learner will learn, the aims and learning objectives).

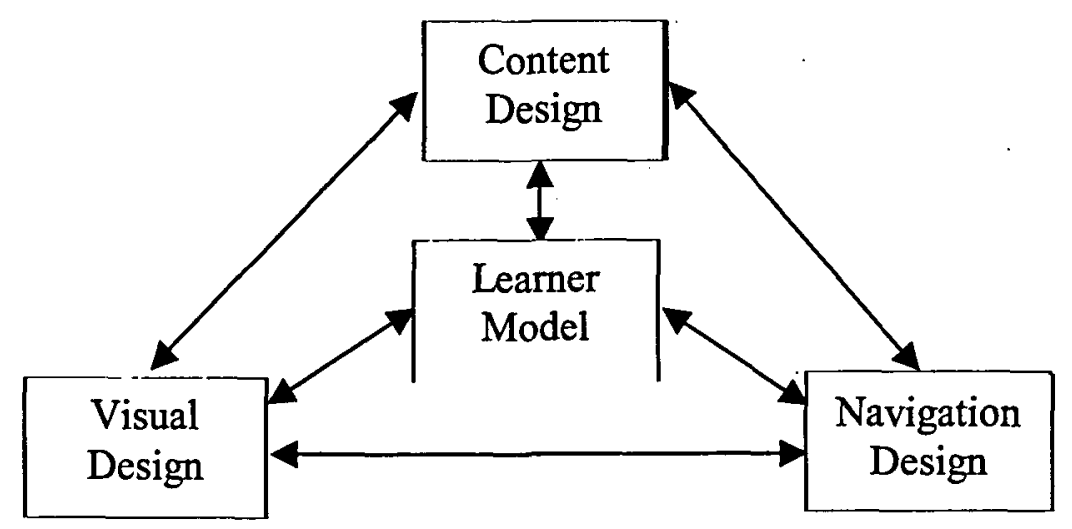

Figure 1: A model of learner-centred courseware design (adapted from Pearson and Green, 1999)

A set of evaluation criteria combining the $\mathrm{W} 3 \mathrm{C}$ guidelines and aspects of learner-centred courseware design was developed. The evaluation criteria were also informed by the results of interviews with a group of students. They were asked about the assistive technology they use, their experiences in accessing the Web and WebCT for learning resources, the difficulties they encountered and the benefits of online learning for them. The resulting set of seventeen checkpoints represents an instrument that is specifically aimed at evaluation of online learning environments as opposed to Web sites in general. Questions included:

- Is the content including page organization, headings and lists consistent?

- Are navigational elements consistent and well structured, do icons and pictorial images make sense?

- Is the content structured in usable chunks, avoiding excessive scrolling and are longer documents organized with links to sections and subsections? 
- Are learning materials presented in an accessible format, and if not, are alternatives provided?

- Is the material accessible to assistive technologies (screen readers, speech recognition software, text browsers, keyboard input, etc.)?

\section{Course evaluation}

Thirty $W e b C T$ courses were investigated. The evaluation was carried out to determine, in particular, the level of accessibility for students with sensory or cognitive disabilities. Attention was paid to the structure, content, navigational design, communication facilities and compatibility of $W e b C T$ with assistive technologies such as screen readers, dictation software and browser settings. The issues raised from an evaluation of the courses investigated and from the interviews of students with disabilities enable the results to be presented in two categories: generic and $W e b C T$-specific considerations.

\section{Students' comments}

Students' comments have been largely integrated into the results presented below, but some specific examples have been selected here to illustrate some of the problems faced by people with different disabilities in accessing courses.

A student with dyslexia found the home page problematic on one course. He relies on the use of visual cues in remembering structure:

The icons are too small, too complicated and the text links contain too many words. I don't know what these icons mean (a wand for evaluation, man at work for assignments), they are not memorable and with the long text links I wouldn't remember where elements of the course belong. Also the background is too busy and interferes with the information I'm trying to look at.

A student with rheumatoid arthritis and diabetes (which can cause eyesight problems) had problems with contrast, PDF documents and long scrolling documents:

The Welcome screen is orange/yellow background, red text; the colour contrast makes it difficult to read. The colours used in the Course outline document are also difficult (orange/yellow with black text) - it blurs when I try to read it. Plain black text on white background is best. There are long scrolling text documents - I would find it confusing and tedious to scroll through all this text to find a particular piece of information. I want to be able to home in on a particular section without going through it all every time.

A student with severe nystagmus and very low reading vision had problems with PDF documents and with the discussion and chat functions:

The online readings (PDF) are too small and the typeface is poor. It is too difficult to read. I would need dictation software to access the chat or discussion areas, but it doesn't seem to work with the chat tool, so it would be useless to me.

A totally blind student found navigating through the WebCT interface tedious, but his main problem was with learning materials presented in an inaccessible format. 
As a law student, I find it particularly frustrating when many of the papers I need are in PDF format, also Powerpoint slides are no use to me online, nor other read-only formats. I cannot use online chat easily because the conversation moves on too quickly for me to read.

\section{Evaluation results - generic}

The analysis of generic issues represents elements of courseware design which are a result of the methods, structure, design and presentation of materials by the designer that may pose difficulties in accessing the learning environment for students with disabilities. These generic issues are not because of any constraints imposed by $W e b C T$ itself. The following were the major problems encountered.

Inconsistent and inappropriate use of icons or graphics

Many students with learning disabilities rely on pictorial cues for navigation or understanding learning objects.

No text equivalents for graphics, figures or other illustrations

This can be a problem for people with vision impairments who rely on screen readers to interpret visual elements in a text format.

\section{Poor organization of content}

There is a general design issue here in the tendency towards 'shovelware' - content intended for traditional delivery is merely uploaded for online delivery. The result is large amounts of scrollable text which is difficult to manage and material which is not 'chunked' for manageability. There is also a tendency not to take advantage of some of the features of $W e b C T$ for organization of content.

The widespread use of PDF file formats for the presentation of text documents

This is a major problem. PDF files cannot always be interpreted by screen reading software. For students with vision impairments for whom the traditional library is totally unusable, the presentation of documents online can be a huge benefit. The latest version of Adobe Acrobat Reader (http://www.adobe.com/products/acrobat/solutionsacchtml) provides an accessible solution, provided the document has been created in the first place in an accessible format. However, documents scanned and saved as graphic image files before conversion to PDF remain inaccessible. There are similar problems with other documents including PowerPoint presentations or movies created in Macromedia Flash.

Text may not be correctly or accurately interpreted by screen readers

This can present problems not just to vision-impaired students but also to those who have difficulty in reading, interpreting or understanding text or complex language. Words in capitals may be read as individual letters, abbreviations may not be recognized, and unusual characters are interpreted literally; for example, the symbol $\sim$ when used as a line separator, will be read as 'Tilda, tilda, tilda, tilda ...' for as many times as the symbol appears.

The use of tables can be a problem for people with disabilities

Because screen reading software reads the information across cells, without appropriate table header descriptions and careful use of layout, the contents of the table makes no sense to the learner.

Poor interface design

While designers may wish to customize their courses to reflect the individual academic and 
course, inappropriate use of foreground and background colours and contrast can make an interface hard to distinguish, read or interpret for people with visual, perceptual or spatial difficulties. Similarly the use of colour to convey important information and inconsistent use of icons can make access difficult for people with vision impairments or learning disabilities.

\section{Evaluation results - WebCT specific}

Whilst it is WebCT's stated aim to meet level one compliance with the W3C accessibility guidelines, some problems remain. The problems identified are not unique to this study (http://www.webct.com/wyw/ViewContent?contentID $=2627931$ ) and the WebCT designers' online discussion forum (http://www.webct.com/webct/forum/topics?discussion=7816\&topic $=21849$ ) has been helpful in highlighting the efforts of others in this regard. In seeking to provide designers with guidelines for inclusive design, it is important to distinguish between features that are subject to their own design decisions, and those factors that are attributable to the $W e b C T$ environment. The main problems encountered to date with features of the WebCT environment are:

There is no text equivalent for some icons in the icon library; some titles and headings are graphics without text equivalents

This is a problem for those using screen reading software. Also the headings cannot be disabled, making it cumbersome for those using screen readers or with slow modem connections.

The use of tables can be a problem

Just as outlined above, tables need to be properly defined to ensure that screen readers can interpret the information they contain.

The overuse of frames

In some instances, it has been reported that up to seven frames may be open on a screen at one time. Once again, this can be confusing for those who rely on screen reading software.

The use of Applets and Java for the implementation of some of the interactive elements of WebCT, including chat windows, discussion groups, the whiteboard and email

This means that they cannot be accessed by students using dictation software, and presents a barrier to those for whom text entry and other forms of communication are difficult. Synchronous chat is very difficult for people who have problems entering text or reading quickly enough. Students complain that the conversation has moved on before they have the opportunity to respond.

We would hope that these issues will be resolved in future versions of WebCT. In any case, many course designers will be using current-and earlier versions for some time.

\section{Staff perceptions}

A short survey was carried out of staff at UNSW who are engaged in the development of online courses to determine their views on and awareness of issues of accessibility to online learning, and to confirm the results of informal discussions with six course developers. The questionnaire was distributed as part of a larger survey via WebCT to a hundred course designers at UNSW, which generated twenty responses. 
Academics at UNSW build whole courses themselves, with support from EDTeC in instructional design, the use of $W e b C T$, and specialist graphics, audio and video services. Discussions with staff reveal that for those who have developed their first course in $W e b C T$, the main concern has been to get material online with limited instructional design support and restricted timescales. Some are not sure whether they have students with disabilities on their course, and are often not aware of the techniques and design methods that would make their courses inclusive. However, having successfully developed a course, the academics are keen to incorporate inclusive design into the new courses they are developing.

The survey results support the anecdotal evidence. A total of 15 per cent of respondents could confirm that there were students with disabilities enrolled on their WebCT courses, while 45 per cent believed they had no students with disabilities and 30 per cent were not sure. There are a number of reasons why staff do not believe or are not sure if they have students with disabilities. It could be a lack of awareness of disability by academics; students may not be registered as having a disability - especially if they have a learning difficulty; students may be reluctant to identify themselves as having a disability; or they may not be aware themselves that they have a disability. This final point is particularly true of some students with specific learning difficulties (such as dyslexia). Students might identify themselves to the Equity and Diversity Unit only if they believe they. require particular assistance.

Staff were asked to indicate the type of disability their students have. This revealed that a range of disabilities is encountered: learning/physical disability, physical/ sensory disability and sensory disability. When asked if they had been able to take account of learners with disabilities in the design of their $W e b C T$ courses, 45 per cent believed that they had, 5 per cent said they had not, and 50 per cent did not know. However, 55 per cent of designers also expressed an interest in receiving training in the design of inclusive courses.

\section{Discussion and outcomes}

\section{Guidelines}

Ideally, the needs of learners with disabilities should be addressed at the design stage rather than attempting to retrofit solutions. While existing courses can be improved, through training, awareness and support, designers can create courses that meet the needs of most of their learners most of the time.

A structured approach is required to help academics develop accessible courseware. At a general level, staff should be encouraged to use the available features of the learning environment effectively. This would help in the structuring of the environment and in making the transition from traditional to online learning. Staff awareness needs to be raised of the available guidelines (such as W3C), checking facilities (Bobby), and software development support (such as Macromedia's accessibility extension for Dreamweaver Four and UltraDev for checking the validity of Web pages as they are created). Above all, designers also need support in developing learner-centred courseware (Harper and Hedberg, 1997).

The findings of the investigation have been distilled into a set of guidelines (Pearson and Koppi, 2001) for academic designers of courses in WebCT, but which are generally 
applicable to all Web-based learning environments. The guidelines take the form of checkpoints, with advice, hints, practical examples and techniques for implementation - a 'how to' guide. The guidelines are available from http://www.edtec.unsw.edu.au. This form of guidelines (which relate to those of W3C) is more useful to academic staff than the technical W3C guidelines which are not specifically aimed at the academic designer of online learning environments. The checkpoints employed by these guidelines are summarized as follows:

- ensure consistent and appropriate use of graphics, icons and other visual cues;

- ensure all graphics, figures, and other illustrations include a text equivalent;

- organize content to take account of the transition to an online environment;

- use the features provided by $W e b C T$ to organize and structure course content;

- make PDF and other read-only file formats accessible;

- be aware of the limitations of screen readers in interpreting unusual text, characters and abbreviations;

- ensure that tables are carefully and appropriately used;

- ensure appropriate use of colours and contrasts in screen design;

- provide alternative sources of information for video or audio.

Each checkpoint includes:

- an explanation of its relevance to accessibility;

- advice and practical examples illustrating how to implement the checkpoints using WebCT and Dreamweaver (the predominant Web authoring software available to academics at UNSW and UoT);

- referential links to further information where appropriate;

- a reference for each checkpoint to the relevant W3C guideline(s).

The document includes a second section which advises the designer on methods of checking their courses and resources for accessibility including using the available checking tools, simple manual checking methods and reference to EDTeC's 'Quality Teaching Principles and Guidelines' (http://www.edtec.unsw.edu.au) for more advice on design issues.

\section{Dissemination and future work}

These guidelines were developed for staff at UNSW and others using the WebCT environment - but they have universal application. There is clearly a demand for similar more generic guidelines across the academic community and there is scope for further related work. The University of Teesside is beginning to implement BlackBoard as the environment to support online learning. Since WebCT and BlackBoard are currently two of the most popular commercially available online learning environments worldwide, the guidelines will be extended to include specific advice for users of BlackBoard as well as WebCT.

We intend to carry out a detailed evaluation of the guidelines and their effectiveness in 
assisting the academic in inclusive course design and development. Other academics and institutions are encouraged to use the guidelines in the development of their own courses, and their feedback will be sought in developing and extending the guidelines.

In response to the results of the survey, which indicated a need for training in accessible design, we have developed a series of training workshops to give staff hands on experience of assistive technologies and practice in accessible design. Initially these workshops form part of the UNSW suite of training workshops. They will then be extended to the University of Teesside as they develop their support program for BlackBoard, and subsequently to other centres and universities.

In addition, we have developed an online course, based on the guidelines, in accessible course design which is being used in the professional staff development program at UNSW and also as a postgraduate module at UoT.

\section{Conclusion}

At the end of this stage of the project, we have been able to present an analysis of the problems encountered by students with disabilities in the use of Web-based learning. As a result of this analysis, a set of proposals for the design of online courseware that is accessible not just to those with disabilities, but to all students, has been developed. These proposals have been distilled into practical guidelines presented in a 'user-friendly' manner for academics who simply want to get their courses online in the most efficient and accessible way. The next stage has been the development of workshops and an online course in accessible design which build on the guidelines and provide the opportunity for a better understanding of issues, techniques and tools in accessible design.

The key to accessible courseware is to take a learner-centred design approach, one which takes account of the needs of the learner. Although one cannot expect always to meet all the needs of every learner, reasonable steps can be taken to ensure the widest participation. Even if we are not meeting the needs of all potential users we should be aware of exactly who we might be excluding. Designing for inclusion provides the opportunity to develop accessible courses for all students, and the move to online learning prompts us to improve our teaching and learning practices for all our students.

\section{Acknowledgements}

This project has been supported by a Study Abroad Fellowship from the Leverhulme Trust, UK.

\section{References}

Bates, A. W. (2000), Managing Technological Change, San Francisco: Jossey-Bass.

Collis, B. and Moonan, J. (2001), Flexible Learning in a Digital World, London: Kogan Page.

Harper, B. and Hedberg, J. (1997), 'Creating motivating interactive learning environments', Paper presented at the ASCILITE Conference, Perth, 7-10 December. http://www.ascilite. org.au/conferences/perth97/papers/Harper/Harper.html, URL last accessed Jan. 2001. 
Leung, P., Owens, J., Lamb, G., Smith, K., Shaw, J., and Hauff, R. (1999), Assistive Technology: Meeting the Needs of Students with Disabilities in Post-Secondary Education, Insititute of Disability Studies, Deakin University, 99/6.

Pearson, E. J. and Green, S. J. (1999), 'Courseware engineering or design', Association For Learning Technology Conference (Alt-C), Bristol.

Pearson, E. J. and Koppi, A. J. (2001), 'Guidelines for accessible online courses', internal publication, University of New South Wales, http://www.edtec.unsw.edu.au.

'Adobe Acrobat Five', http://www.adobe.com/products/acrobat/solutionsacc.html, URL last accessed 3 April 2002.

CAST 'Bobby Worldwide', http://www.cast.org/bobby/, URL last accessed 3 April 2002.

'Consultations on the Draft Disability Standards in Education', http://www.deet.gov.aul archiveliaelanalysis/ddaedcon.htm, URL last accessed 3 April 2002.

'Disability on the Agenda', http://www.disability.gov.uk/index.html, last updated 6 July 2001, URL last accessed 3 April 2002.

'Quick Tips to Make Accessible Web Sites', http://www.genasys.usm.maine.edulaccess.htm, URL last accessed 3 April 2002.

'Section 504, the Americans with Disabilities Act, and Education Reform', http://www.wrightslaw.com/info/section504.ada.peer.htm, PEER, URL last accessed 3 April 2002.

'Some Thoughts on Accessibility and Universal Design', http://www.webct.com/wyw/ View Content? contentID $=2627931$, Stephen Rehberg, Georgia State University, URL last accessed 3 April 2002.

'Web Content Accessibility Guidelines 1.0', http://www.w3.org/WAI/Resources/\#gl, URL last accessed 3 April 2002.

'WebCT discussion forum on accessibility', http://www.webct.com/webct/forum/ topics?discussion $=7816 \&$ topic $=21849$, URL last accessed 3 April 2002. 